\title{
STABILITY AND ENGINEERING EFFECT OF SHOALS AND CHANNELS IN CAOFEIDIAN DEEP-WATER HARBOR AREA, CHINA
}

\author{
LU Yongjun', JI Rongyao ${ }^{2}$, ZUO Liqin ${ }^{2}$
}

\begin{abstract}
Caofeidian sea area is the only natural site suitable for building a large-sized berth of 300000 tons without excavation of waterways and harbor basins in Bohai Bay. In Caofeidian harbor area, the stability of the shoals-inlets coastal system under natural conditions is a key point. The harbor could be developed only if the coastal system is stable. In this paper the characteristics of waves, tidal currents, sedimentation and seabed evolution in the Caofeidian shoal area is briefly described, and the trend of stability of shoals and channels is predicted based on research on the coastal system formation. Engineering effect of some projects, such as the dam linking the Caofeidian Island and the coastline, the shoal reclamation and ore terminal construction, is also studied. The analysis show that deposition and erosion of the seabed in front of Caofeidian foreland will reach its equilibrium in $2 \sim 3$ years after the implementation of the proposed scheme.
\end{abstract}

Keywords: evolution of shoals and channels; stability; deep-water harbor; Caofeidian; Bohai Bay

\section{INTRODUCTION}

Caofeidian harbor area is located in the north side of Bohai Bay mouth (Fig. 1). Caofeidian Island is originally a NE-SW strip barrier island and is about $18 \mathrm{~km}$ far away from the coastline. The area of the barrier island above the mean sea level is about $8 \mathrm{~km}$ in length and $1 \mathrm{~km}$ in width. The nearshore sea area of Caofeidian is of satisfactory condition for building a port. "There are deep channels in the seaward side and shoals in the landward direction." This provids the most compelling for the construction of large deep-water port as well as the development of near-harbor industry. The $30 \mathrm{~m}$ water depth coastline in front of Caofeidian is $6 \mathrm{~km}$, without problems of frozen and deposition, and it is the only natural site for building a large-sized berth of 300000 tons without excavation of waterways and harbor basins in Bohai Bay. The area of the shoals between Caofeidian Island and the coastline is $450 \mathrm{~km}^{2}$ in size, and it may provide enough space for the layout of port industry and the development of the city. Caofeidian is adjacent to the metropolis circle of Beijing, Tianjin and Hebei Province, a core area of economic development in North China. Its hinterland is the most central region for production of coal, steel, building materials and chemical industry raw materials. While it also greatly demands crude oil and iron ore, etc. However in the past, the coast along the Bohai Bay was restricted by the lack of deep water coastline resources, large berths with a tonnage of over 200000 were scarce. Thus, the construction of deep water harbor and relevant industry in Caofeidian is not only of unique resources superiority, but also due to its location in the front edge of economic circle of Bohai Sea. The development and construction of Caofeidian Harbor basin can eliminate the bottleneck of energy sources and raw materials in North China and raise the layout and integral function of ports along the Bohai Sea.

In Caofeidian harbor area, the long-term stability of the coastal system, which consists of shoals and inlets under natural conditions (strong ocean dynamic forces, especially storm surges) is a key point. The harbor could be developed only with the stable coastal system. The coastal system will be altered to some extent during various stages in the construction of harbor and will be gradually adjusted under hydrodynamic forces. The harbor construction should have little influence on the basic stability of the coastal system (Liang, 2008). Regarding whether or not the vast shoal reclamation's influence on the hydrodynamic environment of the deep channel in front of Caofeidian, many research institutes including Nanjing Hydraulic Research Institute, have carried out theoretical studies, numerical and physical model tests(Xu, 1997; Wang et al, 1997; Lu et al, 2006; Xu et al, 2007). According to the above research, a layout scheme of "island in the front and land at the back" and an excavated harbor basin consistes of various tidal inlets (Zhang et al, 2006) was proposed (Fig. 1). During the construction in recent years, the field observations have proved the creditability of the predicated results so as to be helpful for the continuous implementation of the proposed planning (Qiu, 2008). In this paper the formation mechanism of the shoals and inlets of Caofeidian is briefly dicussed, its stability is analyzed, and its evolution tendency is predicted based on the engineering effect of recent projects.

\footnotetext{
${ }^{1}$ State Key Laboratory of Hydrology-Water Resources and Hydraulic Engineering, Nanjing Hydraulic Research Institute, 223 Guangzhou Road, Nanjing, 210029, China

${ }^{2}$ Nanjing Hydraulic Research Institute, 223 Guangzhou Road, Nanjing, 210029, China
} 


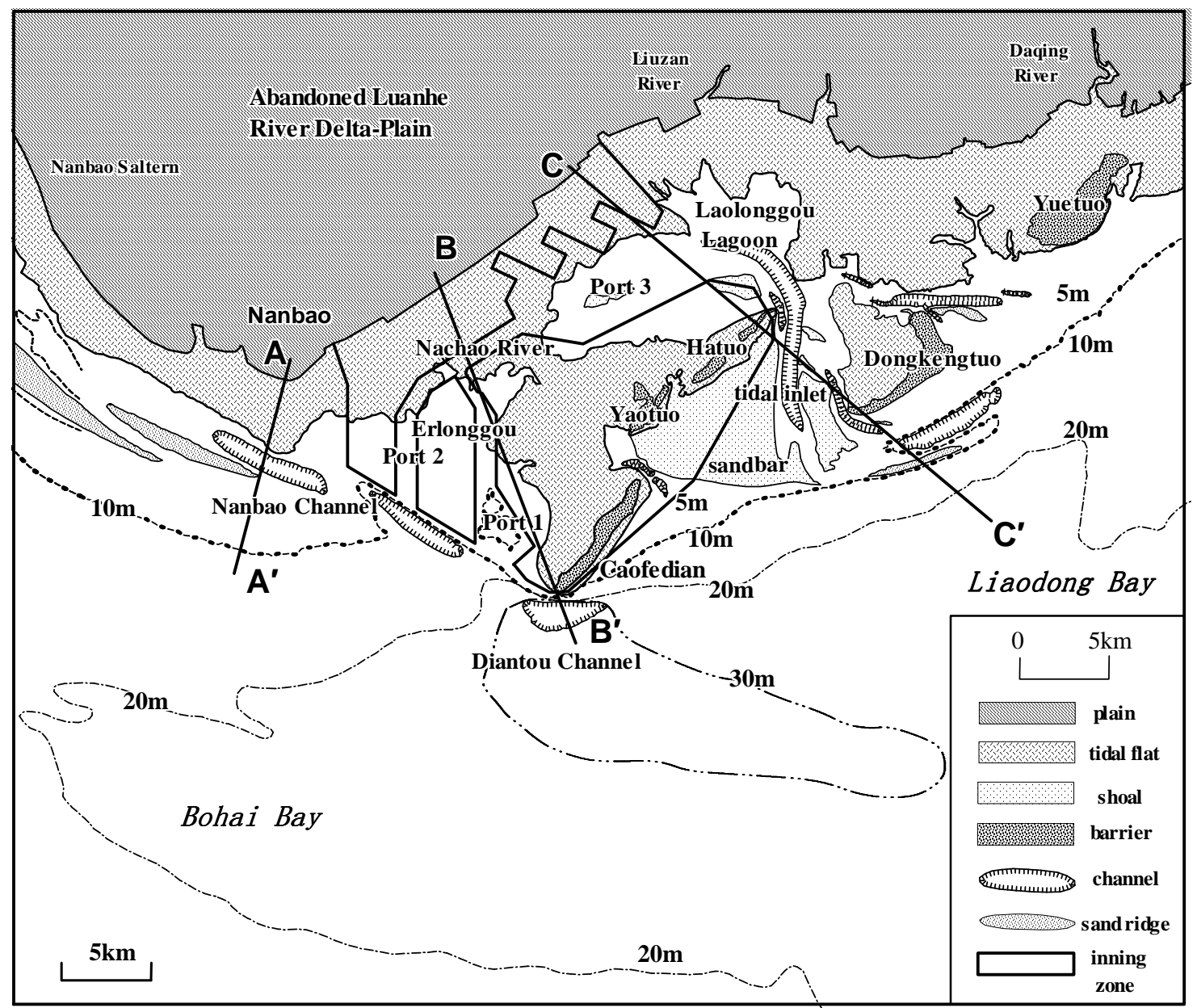

Figure 1. Layout of coastal system and proposed scheme in Caofeidian sea area (Ji, 2008)

\section{MORPHOLOGIC FEATURES OF CAOFEIDIAN COASTAL AREA}

The Caofeidian sea area is located in the transitional zone between Bohai Bay and Liaodong Bay. The section of Daqing River estuary-Nanbao possesses double coastline characteristics. The continental coastline at the inner side is the grown alluvial plain along the front of the abandoned Luanhe River Delta. The topography is low and even, with an elevation of $1 \sim 3 \mathrm{~m}$, and there are barren shoals and salt fields along the coast. The sandy island coastline at the outer side consists of Caofeidian, Yaotuo, Hatuo and Dongkengtuo barrier islands and basically has the same direction as the land line. There are lagoon bays and tidal flats between the barrier islands and the land. Deep channels for tidal inlets grow between barrier islands (Fig. 1). There are 3 relatively independent topographical systems along this section ( $\mathrm{Ji}, 2008$ ). The deep channel system mainly consists of Caofeidian Island and the deep channel in front of it. Laolonggou barrier-lagoon system mainly consists of barrier islands of Hatuo and Dongkengtuo, Laolonggou lagoon bay, deep channels for tidal inlets as well as entrance sandbars. Nanbao coastal system mainly consists of Nanbao deep channel and tidal sand ridges outside the coastline (Fig. 1).

\section{Deep Channels and Shoals in Front of Caofeidian}

Caofeidian Island is located at the turning point of the north coastline of Bohai Bay and extends southward into Bohai Bay in the form of headland. Before the harbor construction, Caofeidian Island is originally a NE-SW strip barrier island, and there is a large shoal area between its north side and the landline. The mean water depth is about $1.5 \mathrm{~m}$. Most of the shoal area is submerged during the high tide period and appears above the water surface during the low tide period. The sea area of deep channel is just in front (South side) of Caofeidian Island. The underwater slope is steep. The $30 \mathrm{~m}$-contour is about $400 \sim 500 \mathrm{~m}$ away from the coast (Fig. 2), which is the deepest in the whole Bohai Bay. The natural water depth is generally larger than $25 \mathrm{~m}$, even reaching $41 \mathrm{~m}$. The '>30m depth' area is $26 \mathrm{~km}$ 
in length and about $3.5 \sim 7.5 \mathrm{~km}$ in width (Fig. 1). It develops into an area with strongest tidal currents in this sea area under the headland effect. It is the main dynamic force to maintain the water depth of the deep channel.

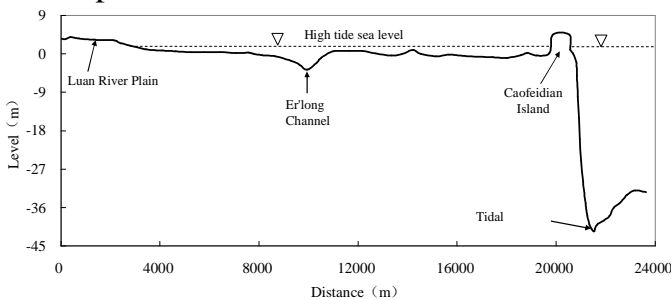

Figure 2. Topography of typical cross section BB' in Caofeidian sea area

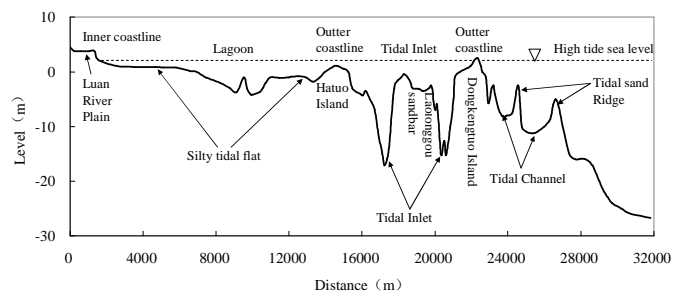

Figure 3. Topography of typical cross section $\mathrm{CC}^{\prime}$ in Laolonggou in Caofeidian sea area

\section{Laolonggou Offshore Sand Barriers-Lagoons}

Laolonggou barrier-lagoon coast system mainly consists of topographical components including barrier islands, lagoon and deep channels for tidal inlets (Fig. 1). Among which, the sand barriers are divided into two nearly parallel inner and outer rows. The inner row is Hatuo-Yaotuo-Caofeidian barrier islands, and the outer row is made up of Dongkengtuo and Yuetuo barrier islands. The presence of the offshore sand barriers results in the double coastlines in Caofeidian sea area and the separation of lagoon shoal at the inner side of the sand barriers from the open sea, leading to different dynamic conditions and topographical features between them. The lagoon area of Laolonggou at the inner side of the sand barriers has an area of about $350 \mathrm{~km}^{2}$, and there is a large area of grown silty tidal flat. The shoals above the elevation of $0 \mathrm{~m}$ have an area of $160 \mathrm{~km}^{2}$. There are deep channels in the lagoon, and the largest water depth is up to $21 \mathrm{~m}$; divided by Dongkengtuo, there are east and west mouths to connect with the outer sea (Fig. 1). The water and sediment from Liuzan River is very small, and the influence of the runoffs on the lagoon may be neglected; owing to the sheltering of the offshore sand barriers, the waves from the outer sea mostly break in the shallow water area outside the offshore sand barrier, accordingly, the dynamic influences of waves in the lagoon is weak. Furthermore, the mean tidal range in this sea area is small, and the mean water depth in the shoal is only about $1.5 \mathrm{~m}$. Therefore, with the rise and drop of flood and ebb tides, large area of floodplain currents arise, and most of their kinetic energy is dissipated due to friction and their velocity is small.

Though the mean tidal range in this sea area is small, there is vast quantity of tidal amount in the lagoon owing to large water area, and the dynamic forces of the flood and ebb tides are strong. Thus, a large deep channel for tidal inlets at Laolonggou is aroused between offshore sand barriers. Divided by Dongkengtuo, the Laolonggou deep channel is divided into eastern and western branches. The eastern branch is almost in E-S direction, and its scale is smaller than that of the western branch. It is about 13 $\mathrm{km}$ in length. At present, the 2 m-deep channel is smooth all the way, about $200 \sim 1200$ in width, and the largest water depth is about $19 \mathrm{~m}$. The western branch is the main part of Laolonggou tidal inlet, originated from the lagoon at the north side of Hatuo, enters into the sea in a direction of N-S. It is 17.5 $\mathrm{km}$ in length and 2 12 km in width. The $5 \mathrm{~m}$-deep channel is smooth all the way. The largest water depth is up to $22 \mathrm{~m}$. There exist entrance sandbars at mouths of the eastern and western branches. As for the western branch, the $2 \mathrm{~m}$-deep channel near Hatuo is $2 \mathrm{~km}$ in width and it rapidly extends to 11 $\mathrm{km}$ in width near Dongkengtuo, and the ebb tides gradually diffuse and sediment continuously deposits so as to form large-scale sandbars; the water depth and width of the deep channel gradually decrease towards the sea, the largest water depth near Hatuo is $22 \mathrm{~m}$ and becomes $5 \mathrm{~m}$ near the entrance andbar, and correspondingly, the width of the $5 \mathrm{~m}$-deep channel of $1800 \mathrm{~m}$ becomes $330 \mathrm{~m}$.

\section{Nanbao Deep Channel-Tidal Sand Ridges}

The coastal section of Nanbao has similar geographical features of headland to Caofeidian. The former is located at the turning point of the continental coastline at the inner side, and the latter is at the tuning point of the barrier island coastline at the outer side. The offshore area near Nanbao is of typical underwater topographical features of shoal-channel-ridge (Fig. 4). The shoals belong to muddy and silty ones including clayey silty sand or silty fine sand; the shoals are $2 \sim 4 \mathrm{~km}$ in width, the slope is gentle, about $0.38 \% \sim 0.94 \%$. There are two strip tidal sand ridges about $2 \mathrm{~km}$ away from the shoals. The shallowest water depth is only $1.2 \mathrm{~m}$ at the top of the sand ridge. The sand mass with the water depth less than $3 \mathrm{~m}$ is about $300 \sim 500 \mathrm{~m}$ in width and over $7.5 \mathrm{~km}$ in length (Fig. 1). Nanbao deep channel, 
the narrow and long tidal inlet between the ridge and tidal flat, is nearly parallel to the shore. The $10 \mathrm{~m}$ deep channel within it is about $5 \mathrm{~km}$ in length and $900 \mathrm{~m}$ in width. The deep channel is close to $0 \mathrm{~m}$ contour as well as Nanbao headland, and the largest water depth is up to $16 \mathrm{~m}$.

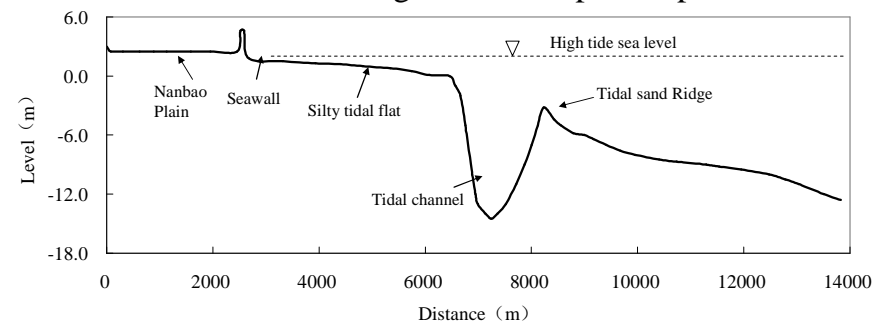

Figure 4. Topography of typical cross section AA' in Nanbao area

\section{CHARACTERISTICS OF WATER AND SEDIMENT MOTION}

Only some small rivers such as Daqing River, Liuzan River directly enter the Caofeidian sea area, and the tide-receiving amount of Bohai Bay is vast, the rivers have no remarkable influences on the studied sea area. The influences of the runoffs may be neglected regarding that the morphodynamic system of this area, the tidal currents, waves and the sediment motion under their co-action are the main dynamic forces for its evolution and stability of shoals and channels.

\section{Characteristics of Tides and Tidal Currents}

Caofeidian sea area is mainly controlled by Bohai tidal wave system(Su, 2005). The tides belong to irregular semidiurnal ones. The mean tidal range in the area gradually increases from the east to the west. According to the statistics, at Caofeidian island, the mean high tidal stage is $0.81 \mathrm{~m}$, the mean low tidal stage is $-0.73 \mathrm{~m}$, so that the tidal range is $1.54 \mathrm{~m}$ ( $\mathrm{Lu}$ et al, 2006). Based on the data analysis of synchronous observation (water, sediment and tides) in Oct. 1996, Mar. 2005, Mar. 2006 and Jul. 2006, the tida current in the deep channel at the south side of Caofeidian island are basically E-W direction reciprocal current (Fig. 1). Though the tidal range is small, the unique headland effect of Caofeidian island leads to the area to possess strongest tidal currents in the study area. It is also the main dynamic forces to maintain the deep water depth. In Mar. 2006, the measured largest velocity of the flooding currents during the spring tides (tidal range: $1.7 \mathrm{~m}$ ) was $1.24 \mathrm{~m} / \mathrm{s}$, and that of the ebbing currents was $0.94 \mathrm{~m} / \mathrm{s}$. In the offshore shallow area, the direction of the main currents has a tendency along the shore or the contours owing to the topographical variation. The floodplain currents dominate in the shoals at the north side of Caofeidian island, and their convergence and diffusion are the main dynamic forces to maintain various tidal inlets.

\section{Characteristics of Waves and Storm Surges}

The direction of the prevailing waves in this sea area is $\mathrm{S}$, with the occurrence frequency being $8.6 \%$; that of the secondary prevailing waves is SE, with the occurrence frequency being $5.8 \%$. The direction of strong waves is ENE, and their wave energy is $16.5 \%$ in proportion, and that of secondary strong waves is NW and NE, with the wave energies being 9.9\% and 9.1\% (Lu et al, 2007), respectively. The wind and waves obviously influence the sediment concentration. As for the medium waves and surges $\left(H_{1 / 10}>1.8 \mathrm{~m}\right)$, the wave energy is $34.0 \%$, indicating that medium waves play a great role in the evolution of coastal shoals. The waves' influence is mainly reflected by the formation of sand barriers owing to horizontal sediment transport and by the erosion of tidal flats while the along-shore sediment transport is relatively weak. In order to analyze the mean wave conditions, the elements of representative waves in the west and east directions were calculated by the mean wave energy method according to the directional statistical results in 1996, 1997 and 1999, which provided by National Marine Environmental Forecasting Center of China. The direction of the statistical waves employ the NE-S waves to analyze the representative east waves, and the SSW-WNW waves to analyze the representative west waves. The analytic results show that the occurrence frequency of east waves in Caofeidian Harbor area is $47.4 \%$, the wave direction is SE by E with a deflection of $6^{\circ}$, the height of the representative waves $H_{1 / 10}=0.77 \mathrm{~m}$, and the corresponding wave period is $3.5 \mathrm{~s}$; the occurrence frequency of west waves is $27.6 \%$, the wave direction is SW by W with a deflection of $5^{\circ}$, the height of the representative waves $H_{1 / 10}=0.57 \mathrm{~m}$, and the corresponding wave period is $3.1 \mathrm{~s}$.

The coastal area of Bohai Bay is one of regions with the most severe storm surges in China. According to the statistical data during 1950 1981 at Tianjin Port, there were 253 storm surges with 
the increased water over $1 \mathrm{~m}$ in height, with the annual value of 7.9 tides; there were 7 storm surges with the increased water over $2 \mathrm{~m}$ in height, with the value of once per 4.6 years; the largest value of increased water is $2.52 \mathrm{~m}$ (in Nov. of 1960). Storm surges mainly occur in autumn and winter, $76.2 \%$ time of the total year, and it is aroused by E and ES winds. The storm surges in Caofeidian sea area is basically the same as that in Tianjin Port, however, because it is located in the abrupt position at the north of the mouth of Bohai Bay, lack of geological conditions for gathering water mass, the amplitude of water increase and decrease is only about 60\% 70\% of Tanggu (Lu et al, 2006; Lu et al, 2007).

\section{Sediment Sources}

Caofeidian sea area is a region with strong windy waves. Long-term stability of the shoals and channels is resulted from the equilibrium of the marine dynamic conditions, coastal boundary conditions as well as sediment conditions for long time. Because only small rivers such as Liuzan River and Daqing River directly enter, the incident water and sediment from upstream are so scarce that their influences can be ignored. The sediment carried by the alongshore currents, from the Luanhe River estuary about $45 \mathrm{~km}$ away the Daqing River estuary in the northeast, may play a role in the evolution of the shoals and channels in the studied area and is one of the most important sediment sources of Caofeidian sea area.

Caofeidian sea area is developed by horizontal action of waves on sediment of abandoned Luanhe Rive delta (Xu, 2008). Rich sediment from Luanhe River is the basic condition for the formation and growth of the coastal topography. Therefore, the evolution of the coastal area closely relates with sediment conditions of Luanhe River. Owing to the construction of reservoirs and water diversion projects in the upper Luanhe River since the 1960s, most water and sediment were intercepted, only small amounts can be discharged from the spillways during the flood period. Table 1 gives the amount of sediment and water from Luanhe River since 1929. which reflects that since the middle period of the 1960s, the seaward sediment transport gradually decreases; since the 1980s, due to the influences of the reservoirs and water diversion projects, the amounts of seaward water and sediment abruptly decrease. The annual mean sediment from Luanhe River is up to 24450000,10110000 and 1671000 t during $1929 \sim 1969,1970 \sim 1979$ and $1980 \sim 2003$, respectively, and that during 1980 2003 is only $10.8 \%$ of the perennial mean value; in 2001 and 2002, runoffs and sediment not even existed. The abrupt decrease of sediment amount from Luanhe River and the shortage of sediment supply result in slight erosion of sand barriers along the coast. Under the action of waves, the sediment of sand barriers mainly moves horizontally and transports towards their inner side. The presence of residual barrier islands in Caofeidian sea area also reflects the decrease of incident sediment amount and short sediment supply. Therefore, the sediment sources in Caofeidian are mainly from the sediment generation of the local seabed. In addition, more and more strong human activities become an important factor to the sediment sources of Caofeidian sea area. For example, construction of reservoirs and locks in the upstream of watercourses, sealand reclamation, artificial sand dredging in sea areas as well as coastal projects, etc., result in less and less sediment sources, and it will further reduce sediment supply to Caofeidian sea area.

\begin{tabular}{|c|c|c|c|c|c|c|c|c|c|}
\hline \multicolumn{1}{|c|}{ Table 1. Statistics of runoffs and sediment discharge from Luanhe River to Bohai Bay in different times } \\
\hline Period & $1929-$ & $1940-$ & $1950-$ & $1960-$ & $1970-$ & $1980-$ & $1990-$ & $2000-$ & $1929-$ \\
& 1939 & 1949 & 1959 & 1969 & 1979 & 1989 & 1999 & 2003 & 2003 \\
Annual water amount $/ 10^{8} \mathrm{~m}^{3}$ & $/$ & $/$ & 5.33 & 3.52 & 3.72 & 0.73 & 1.95 & 0.02 & 2.38 \\
Annual sediment amount $/ 10^{4} \mathrm{t}$ & 37.12 & 19.34 & 24.83 & 16.55 & 10.11 & 0.88 & 3.08 & 0.12 & 15.42 \\
\hline
\end{tabular}

\section{Characteristics of Sediment Transport}

Under the conditions of slight or no waves, the sediment concentration in Caodeidian sea area is not large. Hydrological measurements in recent years showed that the sediment concentration of the water column in the offshore area is generally larger than that of outer sea. It is about $0.05 \sim 0.10 \mathrm{~kg} / \mathrm{m}^{3}$ in the deep water region of outer sea, and about $0.07 \sim 0.15 \mathrm{~kg} / \mathrm{m}^{3}$ in the offshore area. The offshore water area is bounded by Caofeidian island, the mean sediment concentration in the western side is obviously larger than that in the eastern side. For example, as for the mean sediment concentration of spring tides, the measured values of the west and east areas are $0.39 \mathrm{~kg} / \mathrm{m}^{3}$ and $0.32 \mathrm{~kg} / \mathrm{m}^{3}$ in Oct. 1996, $0.163 \mathrm{~kg} / \mathrm{m}^{3}$ and $0.072 \mathrm{~kg} / \mathrm{m}^{3}$ in Mar. 2005, and $0.137 \mathrm{~kg} / \mathrm{m}^{3}$ and $0.054 \mathrm{~kg} / \mathrm{m}^{3}$ in Mar. 2006, respectively. The analysis indicates that the sediment motion aroused by windy waves is the most important factor for variation of sediment concentration in this sea area, and the tidal currents have weaker influences. In recent years, the mean sediment concentration generally has a tendency to 
decrease, and it relates to the abrupt decrease of sediment amount from Luanhe River. The sediment concentration in west side is obviously larger than that in east side.

Based on the analytic results of grain size of bed material samples in March of 2006, it is known that the distribution of sediment is characterized of fine-coarse-fine from the land towards the sea, and the median diameter is also characterized by being coarse in the shoal and fine in the deep channel with the distribution of water depths. Bounded by Caofeidian island, the distribution of the median diameters has the tendency of "small-to-large" from the west to the east. The median diameter at the west side is $0.008 \sim 0.027 \mathrm{~mm}$, and that at the east side is $0.012 \sim 0.250 \mathrm{~mm}$. The ratio of the median diameters between the east and west sides may reach several times. In the west of Caofeidian island, the sorting of sedimentary deposits is just average. While in the east of Caofeidian island, the sorting of sedimentary deposits is averaged — good—averaged from the coast toward the sea. In front of the east sand barrier the sorting is the best, indicating that it is influenced by the strongest wave dynamics ( $\mathrm{Lu}$ et al, 2006; Yang, 2006).

\section{Dynamic Formation Mechanism for Deep Channels}

The deep channel at Caofeidian island, Laolonggou tidal inlet and Nanbao deep channel are the strongest tidal forces regions in the studied area. The tidal currents are the main dynamic forces to form and maintain the water depth of the deep channel. However, the main reason to cause increase of local tidal currents is that there are distinctively different among these deep channels. The increase of local tidal currents aroused by headland topography is the main dynamic forces for the formation of deep channels in front of Caofeidian island and Nanbao, while the increase of the tidal currents resulted from the return of floodplain currents and the restriction action of narrow mouths is the main dynamic forces for Laolonggou tidal inlet.
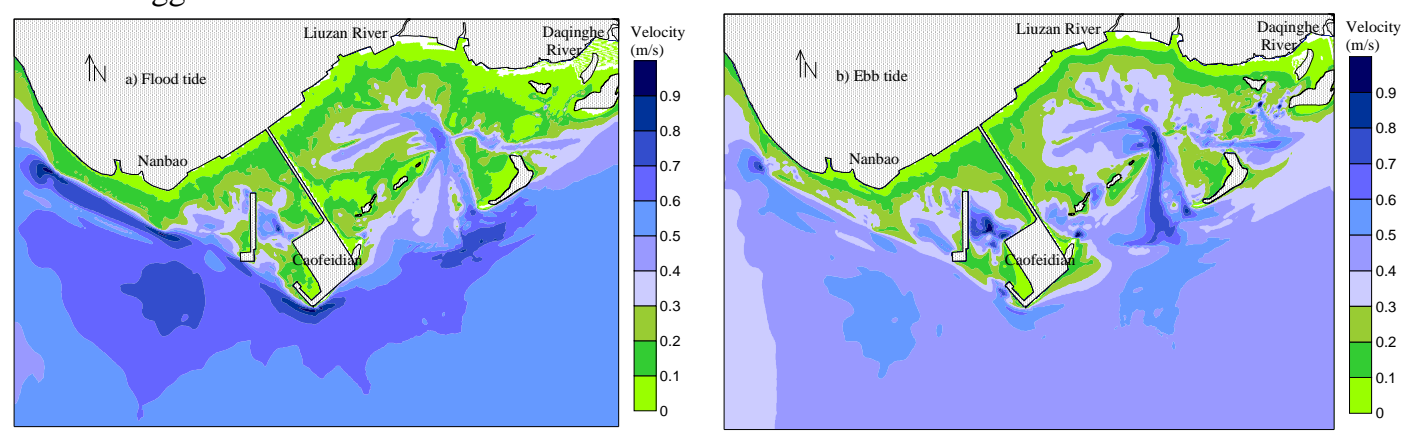

Figure 5. Distribution of mean velocities of flood and ebb tides in Caofeidian sea area (March of 2006)

The sea area in front of Caofeidian barrier island is originally an underwater valley extending from Haihe River estuary to the Bohai Sea strait. Thereby, the growth of the deep channel has certain geological structural basis. However, the deep channel can still maintain its water depth and keep longterm stability even under the conditions of large quantity of sediments from the old Luanhe River, and it closely relates to the increase of local tidal currents in front of Caofeidian owing to its headland topography and to the action of dynamic erosion of tidal currents. The triangle zone protruding southward at north side of Bohai Bay owing to headland topography of Caofeidian will necessarily lead to the increase of tidal currents in local sea areas in front of Caofeidian. Fig.5a and $6 \mathrm{~b}$ show the spatial distributions of mean velocities of floods and ebb tides during spring tide period in March of 2006. It is seen that the increase of local velocities occurs in the water area in front of Caofeidian under the influences of headland topography. That increased zone nearly covers the deep channel area for tidal inlets, furthermore, the velocities gradually decrease with the decrease of the headland effect from the forefront to the outer sea. At the site $500 \mathrm{~m}$ away the front of Caofeidian, the largest mean velocity of flood tides is $0.95 \mathrm{~m} / \mathrm{s}$. At the site about $1000 \mathrm{~m}$ away it reduces to $0.8 \mathrm{~m} / \mathrm{s}$. At the site about $2000 \mathrm{~m}$ away it becomes $0.7 \mathrm{~m} / \mathrm{s}$ (Fig. 5a). The mean velocities of ebb tides there have the same spatial distribution and variation rules ( Fig. 5b). However, the range and amplitude of the velocity increase zone due to the headland effect during the ebb tide period are obviously much smaller than those during the flood tide period. It showed that the increase of local tides and the erosion action aroused by headland effect owing to the diffraction of flood tides around the front of Caofeidian are just the main dynamic conditions for the formation and maintenance of deep channel for tidal inlet. 


\section{EVOLUTION CHARACTERISTICS AND STABILITY ANALYSIS OF SHOALS AND CHANNELS}

The stability of shoals and channels is the key to the evaluation of development and exploitation of sea area. The stability closely relates to the formation factors and evolution stages. Accordingly the analysis of formation and evolution of the morphodynamic system in Caofeidian sea area should be carried out. For the planning and construction of Caofeidian deep water harbor, we need to calculate the deposition and erosion to analyze modern evolution, to summarize the evolution rules and main reasons of deposition and erosion, and to discuss future tendency of stability.

\section{Formation, Growth and Long-Term Variation Tendency of Stability of Shoals and Channels}

Formation and growth of coastal systems The grown coastal morphological system in Caofeidian sea area is the product of deposited materials from the abandoned old Luanhe River delta owing to long-term alternation under the action of waves and tidal currents. Rich sediment from Luanhe River is the basic conditions for the formation and growth of such coastal morphology. Luanhe River ranks the second largest sediment concentration (Yellow River being the 1st) in the whole Bohai Bay, and the annual sediment transport amount is $26800000 \mathrm{t}$ during 1929 1960. Based on the analyses of sediments, ${ }^{14} \mathrm{C}$ dating and archaeological historical data through boring, the separation point of Luanhe River estuary historically migrates and changes many times. Since the Holocene Epoch, there has been 5 secondary sub-delta accumulations of early Holocene Epoch, middle Holocene Epoch, early Historical Epoch, late Historical Epoch and latest Historical Epoch. At present, Daqing River estuary, Dongkengtuo and Caofeidian between Luanhe River estuary and Nanbao were the entrances to the sea for the old Luanhe River. Large quantities of sediments carried by runoffs continuously deposited in the estuarine areas and provided rich sources for the growth of the estuarine deltas. After the alternation of the River, the sediments by runoffs abruptly decreased, the deltas stopped deposition towards the sea, and the coarse sediments in front of it resulted in a series of offshore sand barriers under the action of waves, turbulent waves and tidal currents. Owing to continuous compaction of sediments and long-term erosion by waves, some delta plains gradually subsided and was submerged by water, resulting in lagoon tidal areas at the inner side of sand barriers, accordingly, the offshore sand barrier-lagoon coastal system is formed (Fig. 1).

Caofeidian barrier island is the offshore sand barrier resulted from the horizontal accumulation of the sediments from the old Luanhe River under the action of waves with strong dynamic forces and turbulent waves. According to the analysis of the process of alternation of Luanhe River and formation and abandonment of the delta, the offshore area of Caofeidian has almost experienced the main following evolution stages of dynamic deposition environment chronologically:

Shallow sea deposition environment under dynamic control of tides About 8000 years ago, Nanbao plain area was still wide shallow sea area, the coastline was tens of thousand meters away, and its dynamic deposition environment was similar to that of today's Bohai Bay, China. At that time, no larger rivers entered into the sea area, the wave forces were relatively weak, the sediment motion exhibited slow deposition in the deposition environment under dynamic control of tides, and larger area of muddy tidal flats and silty coasts was grown along the coast.

Rapid delta deposition and development environment under action of runoffs and wave forces $3000 \sim 8000$ years ago, after the alternation of Luanhe River, the old ways of Daqing River entered into Bohai Bay in the Caofeidian sea area. Large quantities of sediment from the upstream deposited in the estuarine areas so as to form estuarine deltas, and their deposition and evolution process was similar to that of the modern Luanhe River delta. That is, the evolution of the deltas was co-acted by runoffs and wave forces. On one hand, large quantities of sediment from rivers deposited and resulted in rapid deposition and development of the deltas towards the sea, on the other hand, the sediments in front of the deltas formed sand barriers under the horizontal transport and sorting by waves. The coastline in this sea area became sandy coast instead of original muddy coast. During the rapid advancing process of Luanhe River delta toward the sea, the sand barrier at the outer side continuously connected with flood plains and destroyed by floods. Simultaneously, new sand barriers were formed at the outer side, and new lagoons grew, leading to new sand barrier-lagoon coastal system. About 3000 years ago, when the delta approached near today's Caofeidian sea area, the embryonic form of Caofeidian barrier island was grown in front of the delta. The investigations (Wang et al, 1997) indicate that the foundation of Caofeidian with sand stratum is deep and thick, the embryonic form of the barrier island starts at the depth of $60 \mathrm{~m}$ from the sea bottom, the sand foundation is over $50 \mathrm{~m}$ in thickness; in $1996,{ }^{14} \mathrm{C}$ dating was analyzed by sampling at $12 \sim 14 \mathrm{~m}$-depth contours at Caofeidian island, and the deposition year is about $3381 \pm 136$ years (Wang et al, 1997). 
Erosion and shrinkage environment of sand barriers under action of waves and tidal currents About 3000 years ago, Luanhe River re-altered, the sediment supply for Caofeidian sea area was reduced greatly, the outer sand barriers in front of the delta were eroded and moved towards inner side, resulting in a series of offshore sand barriers of Caofeidian, Yaotuo, Hatuo, etc. The delta plain became bay-lagoon owing to change of waves and tidal currents and subsidence of compacted sediments. Likewise, Luanhe River entered into the sea through Daqing River estuary and experienced similar deposition and evolution process. At that period, after the growth of offshore sand barrier such as Dongkengtuo, the prototype of Laolonggou coastal morphological system was formed. When Laolonggou offshore sand barrier-lagoon coastal system was formed, the flood and ebb tides could only flow through relatively narrow mouth. The currents became narrow and the velocity increased, leading to the erosion of the deep channel near the mouth. Though the mean tidal range in this sea area is small, there is vast quantity of tidal amount in the lagoon owing to large area for tidal water reservation, and the dynamic forces of the flood and ebb tides are strong. It is the main dynamic forces for the formation and maintenance of water depth of the deep channel for Laolonggou tidal inlet. Because of the alternation of Luanhe river and earliest shortage of sediment sources near Caofeidian and Dongkengtuo, the lagoon mouth has the worst closing degree, and it becomes the bay-type lagoon. In 2006 the detecting results (Wang et al, 2006) of seismic strata for the deep channel along Laolonggou tidal inlet also indicate that Laolonggou is the modern tidal inlet of old river estuary altered by tidal currents. The bottom of the valley is sand and sitly fine sand with a thin layer of clay.

The sea area in front of Caofeidian Island was originally a structural deep channel extending from Haihe River estuary to the Bohai Sea strait, and later it became an underwater valley with certain degree of deposition. When Luanhe River delta approached sea area, the deep channel stopped its seaward advancing to some degree. The underwater valley and modern deep channel for tidal inlet both grew in the structural deep channel. The modern deep channel intercepted the homogenous sand layer in the old valley after the deposition of that layer. It is a newly eroded valley, and a small part of it still followed the old valley (Wang et al, 2006). After the formation of Caofeidian barrier island, obvious velocity increase of local tides was aroused by headland topography, and the seabed was continuously eroded, thus today's deep channel for tidal inlet was formed. Caofeidian headland consisted of loose sediments and was different from the common bedrock headland, and its formation process and how to keep longterm stability were still further studied.

Long-term variation tendency of stability of shoals and channels Caofeidian barrier island is generated in the sandy oceanographic zones under large sediment transport by old Luanhe River, and is an oceanographic sand barrier accumulated by waves and tidal currents with strong dynamic forces. Caofeidian has long development time and thick sand foundation and is stratified by fine sand, silt and clay so that a stable sandy island is formed. Because the large quantities of seaward sediment are the basic conditions for the formation of offshore sand barriers, with the eastward diversion of Luanhe River and the decrease of seaward sediment, the sediment supply in Caofeidian sea area is short. At present, a state of slight erosion and shrinkage occurs along the coast of Yuetuo, Dongkengtuo, Hatuo and Caofeidian. Simultaneously, the coastwise sediment is cut off by tidal ditches, indicating that the longitudinal coastwise sediment supply is not sufficient in this area. From the macroscopic viewpoint, Laolonggou offshore sand barrier-lagoon system is developed owing to the diversion of Luanhe River, the decrease or cut-off of sediment sources as well as the local transgression induced by sea erosion. Thus, offshore sand barrier-lagoon system basically follows the development law during the transgression period. The trend is closed lagoon-semi-closed lagoon-bay-type lagoon, and finally it becomes sea area. However, such a transformation has long-term process, and time for the final transformation should be ten thousand years.

Based on the stratum columns sampled from Laolonggou deep channel, Nanbao deep channel and tidal flat, the 100-year scale deposition rate in Caofeidian sea area is studied by use of ${ }^{210} \mathrm{~Pb}$ activity change (Wang et al, 2006). The test results show that, the sea area and shoal near Nanbao exhibit certain deposition state in recent 100 years, the average deposition rate is about $1 \sim 1.5 \mathrm{~cm} / \mathrm{a}$, it is under strong intensity of human activities, and strong disturbance occurs in the sequence of deposition strata; however, Laolonggou deep channel mainly exhibits erosion, and in recent 100 years, there is no new sediment accumulation in the core sampling area. The seismic section of the deep channel in front of Caofeidian shows that the tidal inlet still keeps complete double-shoulder valley topography, and the valley shoulder close to the head of Caofeidian is not destroyed. Therefore, it will not result in sudden erosion and collapse. Simultaneously, owing to short sediment supply, the deep channel is in a state of slight erosion at present. 


\section{Characteristics of Deposition and Erosion Variation of Shoals and Channels in Recent Years and Analysis of Main Causes}

Fig. 6 shows comparison between depth contours of 1996 and 2006 and distribution of deposition and erosion depths in Caofeidian sea area. It showed that during 1996 2006, the sea area at the outer side of offshore sand barriers generally exhibits a state of erosion, and the depth contours has continuously declined towards the land. The decline rate has a variation rule: it is larger at the west side of Caofeidian than that at the east side. The mean erosion depth of the seabed is usually $1 \sim 2 \mathrm{~m}$. It is worth noticing that in the local sea area close to the west side of Caofeidian terminal, there is a water area of about $5 \mathrm{~km}^{2}$, and the mean erosion depth of the seabed is up to $5 \sim 10 \mathrm{~m}$. The main reason is the excavation of harbor basin and the reclamation of terminals. The subcritical flow zone of lagoon at the inner side of sand barrier mainly exhibits a state of deposition. The area near Laolonggou deep channel exhibit a state of deposition and erosion, and the variation of deposition and erosion is complex. In addition, owing to the influences of human activities in Caofeidian sea area such as the reclamation for aquatic breeding, the coastline has a fast deposition speed and the seaward distance was $1.5 \sim 2 \mathrm{~km}$ in last 10 years. The annual mean deposition speed is about $150 \sim 200 \mathrm{~m}$.

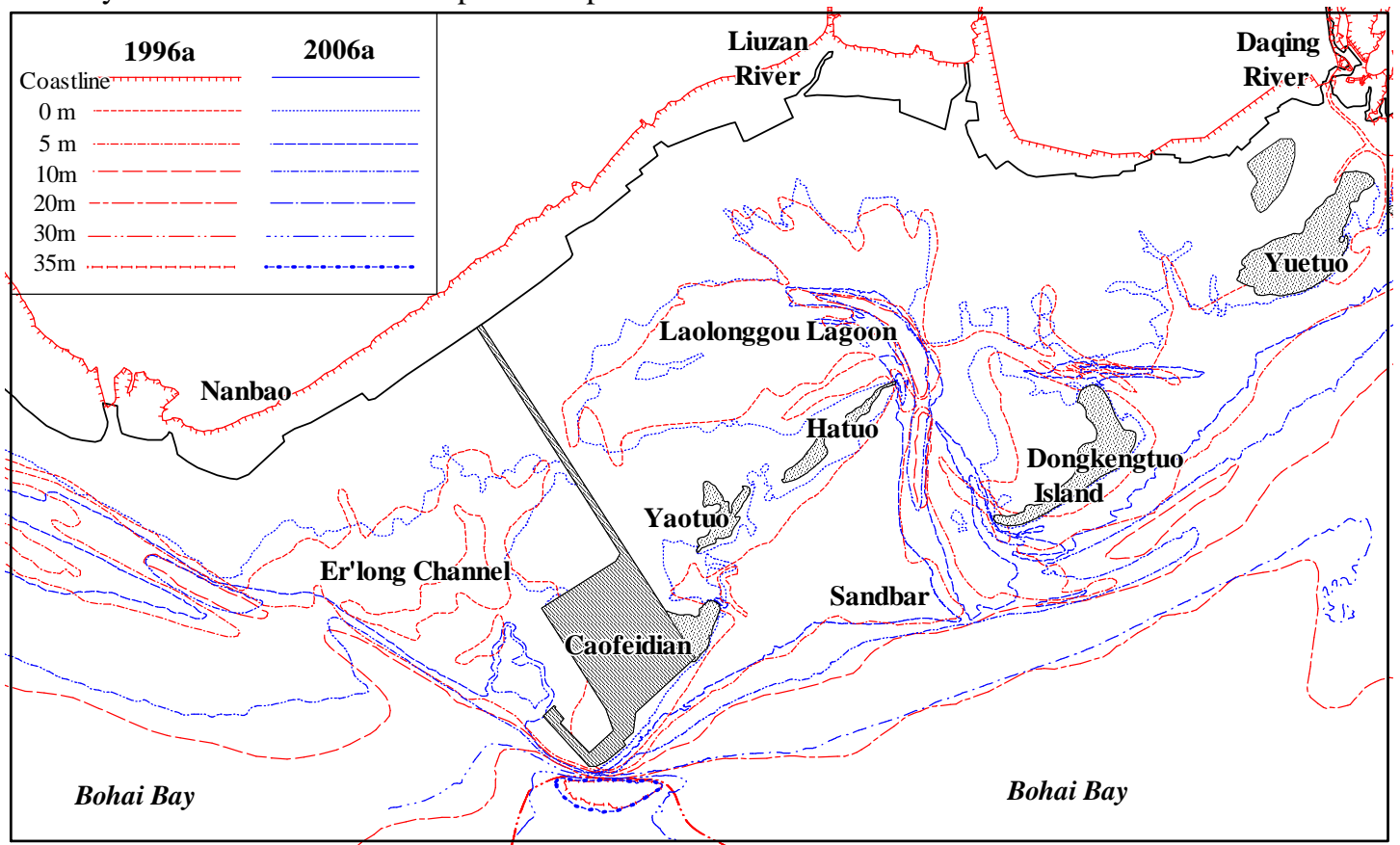

Figure 6. Comparison of depth contours in 1996 and 2006 in Caofeidian sea area

The general state of erosion in Caofeidian sea area relates to the abrupt decrease of seaward sediment transport amount in recent decades and short sediment supply. Under the action of strong waves with the direction of E-S, the sediment on the seabed in the shallow water area at the outer side of Hatuo and Dongkengtuo barrier islands moves horizontally. The horizontal motion of waves and sediment of silty shoals is characterized by the occurrence of erosion in the offshore wave breaking zone, and part of eroded sediment is carried into deep water sea area outside the wave breaking zone and deposits. Owing to the short sediment supply in Caofeidian sea area and the strong alongshore currents in the direction of E-W, most of the sediment in the wave breaking zone lifted by waves is carried to the downstream by the alongshore currents, only small part of sediment is carried away by the currents and deposits in deep water area with weak turbulence of waves. A state of erosion is generally exhibited at the outer edge of Caofeidian and Dongkengtuo barrier islands, and the waterside line has a tendency of transverse displacement toward the coast. In addition, owing to short sediment supply, the sediment concentration in the water is smaller than the sediment transport capacity. Thus the sediment concentration in water currents is raised through continuous erosion of sediment on the seabed, resulting in a state of erosion in the deep water area at the outer side of barrier islands. It can be concluded that the shortage of alongshore sediment supply is the main cause for the erosion in the offshore and deep water areas at the outer side of the sand barriers.

With the development of Caofeidian Harbour area, various human activities such as Caofeidian embankment project, reclamation of harbor basin, construction of terminals, sand dredging and 
excavation of harbor, construction of artificial islands for oil field as well as aquatic breeding in seawater will have increasing influences on dynamic conditions(water, sediment, etc.) and the evolution of shoals and channels. The influences will be stronger and more complex, leading to not only the variation of local hydrodynamic deposition environment but also much effect on the evolution and stability of shoals and channel in Caofeidian sea area. The increasing human activities have greatly changed the dynamic conditions and topographical evolution tendency in Caofeidian sea area and have reached the magnitude of influences by natural factors. In certain coastal areas, the human activities have become the dominating factor for the evolution tendency of shoals and channels. For example, sand dredging pits exhibit strong downward erosion of seabed. Furthermore, during sand dredging period, it will lead to great increase of sediment concentration in water, muddy water transfers and moves with the flood and ebb currents, so as to influence the deposition-erosion evolution in nearby sea areas.

\section{ENGINEERING EFFECT}

At present, the main development projects that have exerted great influences on evolution of dynamic environment and shoals and channels of the coastal system in Caofeidian sea area include Caofeidian embankment project, reclamation of harbor area and construction of terminals, sand dredging from seabed and excavation of harbor basin, etc.

\section{Caofeidian Embankment Project (Dam Linking Caofeidian Island with Coastline)}

Before the development in Caofeidian sea area, there is a large area of shoals between the northwest side of Caofeidian Island and landline. Caofeidian embankment project is located at the ridge of the shoals. The embankment, $18.4 \mathrm{~km}$ in length, is from continent to Caofeidian Island (Fig. 7). The project started in March of 2003, the whole line was finished in May of 2004, and the project was completed at the end of September of 2004.

Under the natural conditions, during the flood period,

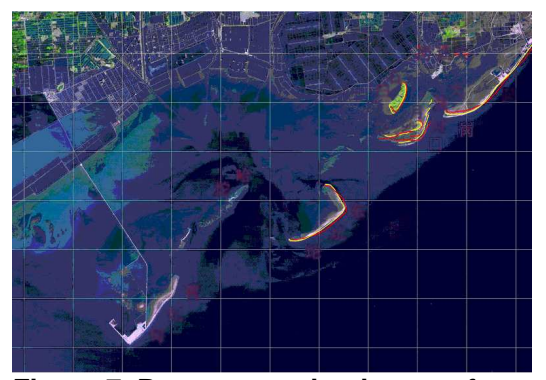

Figure 7. Remote sensing image of Caofeidian sea area in the end of 2005 the tidal currents from Laolonggou and the west tidal inlet gradually submerge the shoals and finally converge near the embankment; during the ebb period, owing to lower shoals at the east side, firstly the water on the shoals including a small part in embankment west side move eastward to Laolonggou. When the tidal stage at the west side decreases to certain degree, the water on the west shoals flows through the west tidal inlet and then enters the deep channel in front of Caofeidian and meets with the water from Laolonggou at the east side. After Caofeidian embankment project is completed, owing to its location in the divergence and convergence zones, the total regime of tidal fields has little variation compared with that before construction. However, the embankment construction intercepts exchange of water from the east and west sides of Caofeidian, especially a small amount of eastward water during the ebb period. Now this small part directly enters the west deep channel.

The contour lines (Lu et al, 2006) of mean tidal velocity (both flood and ebb) variation before and after embankment completion were calculated by mathematical models. Results showed that the mean velocities of flood and ebb tides at the east side of Caofeidian decreased $0.000 \sim 0.030 \mathrm{~m} / \mathrm{s}$, about $0 \sim$ $9 \%$; those in front of Caofeidian have mainly an increasing tendency, that is, $0.005 \sim 0.020 \mathrm{~m} / \mathrm{s}$, the largest increase is $3 \% \sim 4 \%$. Only during the ebb period, the velocity has a slight decrease owing to the influences of local diffraction of currents at embankment head; the velocity of ebb tides at the west side of Caofeidian still has a slight increase, while the velocities of flood and ebb tides in the west deep channel vary little. At the site $1.5 \mathrm{~km}$ away from the front of Caofeidian, there is a slight increase of $0.001 \sim 0.008 \mathrm{~m} / \mathrm{s}$ for both flood and ebb tides, about $2 \%$. At about $3 \mathrm{~km}$ away, a slight increase of $0.001 \sim 0.005 \mathrm{~m} / \mathrm{s}$, about less than $1 \%$. At about $5 \mathrm{~km}$ away, almost no change is detected. The embankment construction separates the water exchange between the east and west sides, the mean velocities of flood and ebb tides in Laolonggou deep channel both have a decreasing tendency, and the largest decrease is $3 \% \sim 4 \%$. The velocity of flood tides has a little change, there is certain increase at the upper part, and there is certain decrease at the lower part with the decrement of $1 \%$. While the velocity of ebb tides has a decrease of $0.01 \sim 0.04 \mathrm{~m} / \mathrm{s}$, especially at the site of $10 \mathrm{~m}$-deep channel, the velocity has a decrease of $0.039 \mathrm{~m} / \mathrm{s}$, about $6 \%$. The main reason lies in that the water flows into Laolonggou from the west to the east for $1 \mathrm{~h}$ during the ebb tide period before the embankment 
completion and cannot flow into Laolonggou after the embankment completion. The tidal stage process in front of Caofeidian almost has no variation ( $\mathrm{Lu}$ et al, 2006), indicating that the embankment construction does not change the tidal structure in Caofeidian sea area.

\section{Reclamation Project}

The reclamation project in the offshore sea area of Caofeidian may be categorized into 2 types: reclamation for aquatic breeding and hydraulic fill of harbor area. In recent 20 years, the scale of marine breeding in Caofeidian has gradually increased. The ponds of fish and shrimp along the coast increase year by year. Large quantities of breeding ponds are constructed in tidal zones, the coastline continuously advances towards the sea, and its front edge has reached the intermediate and low tide shoals. On one hand, the reclamation for aquatic breeding results in artificial coastal topography in the tidal zones, on the other hand, it leads to large scale decrease of natural wetland area. The natural coastal wetland ecosystem has been greatly destroyed. According to the statistics, only at the section from Nanbao to Daqing River estuary, the coastline has advanced $1.5 \sim 2 \mathrm{~km}$ towards the sea owing to reclamation for aquatic breeding during 1996 2006, the annul advancing speed is about 150 $200 \mathrm{~m}$, and the area of shoals has a total decrease of about $96.2 \mathrm{~km}^{2}$. The decrease of shoal area owing to the reclamation for aquatic breeding will also reduce the tidal amount through Laolonggou tidal inlet, weakening tidal forces to some degree.

According to the overall planning of Caofeidian Harbor area, the reclamation area of shoals for the construction of harbor area is up to $310 \mathrm{~km}^{2}$ (Zhang et al, 2006). Dynamic variation and evolution of shoals and channels caused by the reclamation in harbor area are basically the same as those for aquatic breeding. On one hand, the reclamation in harbor area will reduce the area of lagoons and the tidal amount, and will further leads to the corresponding variation of dynamic topography. After the implementation of the planning scheme for the harbor area, the reclamation in harbor area results in the decrease of about $90 \mathrm{~km}^{2}$ of the tidal area of Laolonggou lagoon. The decrease of the tidal amount will lead to the weaker tidal forces in the deep channel of Laolonggou, and the dynamic forces of waves in the sea area of sandbar relatively increase. Accordingly, erosion and shrinkage occur at the outer edge of the delta and sand barriers during the ebb tide period. On the other hand, the reclamation in the harbor area and the embankment construction directly change the coastal shape and morphological structure and results in the straightness and stabilization of the coasts. It will improve the stability of the coasts to some extent. As mentioned above, the offshore sand barrier-lagoon coastal system follows the development trend of closed lagoon-semi-closed lagoon-bay-type lagoon, and finally it becomes sea area. However, after the reclamation in harbor area, the land boundary and mouth of Laolonggou lagoon become stable, the impact of natural evolution factors will be weakened, and it will cahnge the evolution trend of the coastal system to some extent.

\section{Hydrodynamic Conditions and Seabed Deposition-Erosion Variation Aroused by Development Schemes for Harbor Area \\ Introduction of schemes for development of harbor area The water depth in the deep channel} of Caofeidian island is stable, the deep water is close to the coast and it is suitable for the construction of large sized berths. The tidal passages on its both sides are basically stable, and they can be employed as water areas for port services through certain excavation and regulation. Simultaneously, The layout of the overall scheme should be in accordance with the law of water and sediment motion in the sea area, and the existing topographical environment should not be greatly changed. On such a basis, the scheme of a large sized artificial island is to be formed. With Laolonggou and Connecting River as the boundaries, the whole layout of island in the front and land at the back is thus obtained. After comparing various schemes by mathematical models for waves, tidal currents and sediment (Lu et al, 2005; Lu et al, 2006, Lu et al, 2008; Lu et al, 2009), the proposed scheme is shown in Fig.1 (Zhang et al, 2006).

Variation of hydrodynamic conditions after implementation of proposed scheme The implementation of the proposed scheme has different influences on hydrodynamic conditions in various districts ( $\mathrm{Lu}$ et al, 2006): the velocity in deep channel in front of Caofeidian has a slight increase, the mean velocity of the flood tides has an increase of $0.9 \%$, and the mean velocity of the ebb tides has an increase of $5.7 \%$. At the site $1.5 \mathrm{~km}$ in front of Caofeidian, the mean velocity of the flood tides has an increase of $2.4 \%$, and that of the ebb tides has an increase of $1.1 \%$. The slight increase of the velocity is in favor of maintaining the water depth of the deep channel in front of Caofeidian. In the deep channel area of Nanbao, after the implementation of the proposed scheme, the velocity has a slight increase, the 
mean velocity of the flood tides has an increase of $2.2 \%$, the mean velocity of the ebb tides has an increase of $4.1 \%$, the water currents become more smooth, the characteristics of reciprocal currents are more obvious, and they are in favor of maintaining the water depth of the deep channel. In the shoals at the east side of Caofeidian foreland, the reclamation at the east side of harbor area separates the floodplain currents during the flood and ebb tide periods, resulting in that the mean velocity of the flood tides in the shoals at the south side of the reclaimed area has a decrease of $22.0 \%$, and that of the ebb tides has a decrease of $18.0 \%$. The decrease of the velocity will lead to slight deposition in the shoals, and it is in favor of land reclamation and coast stability. Owing to the decrease of tidal amount in the shoals, the velocity in the tidal inlet of Laolonggou has certain decrease, the mean velocity of the flood tides has a decrease of $11.9 \%(0.05 \sim 0.10 \mathrm{~m} / \mathrm{s})$, and that of the ebb tides has a decrease of $18.4 \%$ $(0.1 \sim 0.2 \mathrm{~m} / \mathrm{s})$. It is in favor of the navigation instead of the maintenance of water depth.

As for the proposed scheme, though the reclamation area of the harbor area is about $310 \mathrm{~km}^{2}$, the water depth of the shoal surface is smaller than $1 \mathrm{~m}$ and the mean velocity is smaller than $0.1 \mathrm{~m} / \mathrm{s}$. The reclamation proportion is only $0.3 \% \sim 1.7 \%$ so that the decrease of the tidal amounts is very small compared with pre-construction. Therefore, the development of the harbor area has small influences on the hydrodynamic environment nearby. Fig.8 showed that after the scheme implementation, the velocities at the sites $5 \mathrm{~km}$ away from the south and west sides and $10 \mathrm{~km}$ away from the east side of Caofeidian island have a decrement of being smaller than $2.0 \%$, which is about $0.01 \sim 0.02 \mathrm{~m} / \mathrm{s}$.

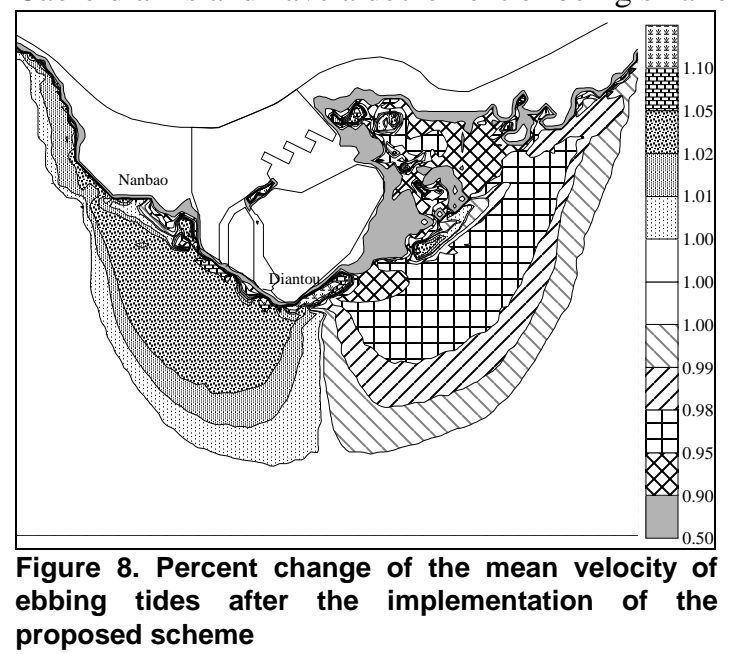

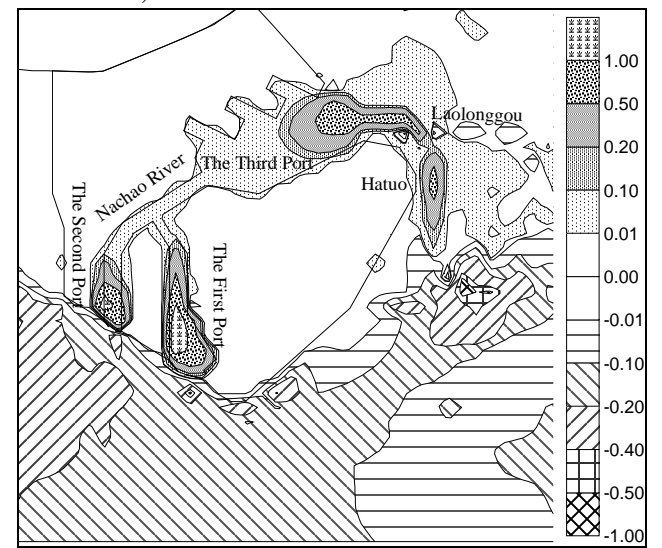

Figure 9. Distribution of deposition and erosion depths after the implementation of the proposed scheme

Deposition-erosion variation of seabed after implementation of proposed scheme ( $\mathrm{Lu}$ et al, 2006; Lu et al, 2009) Based on the preliminary verification of seabed, deposition and erosion of the proposed scheme under the co-action of perennial waves and spring and middle tides were calculated. According to the analysis of wave data, in Caofeidian sea area, the regular direction of waves is SE with a deflection of 6 degrees toward the east and SW with a deflection of 5 degrees toward the west, and their frequencies are $47.4 \%$ and $27.6 \%$ respectively. After the implementation of the proposed scheme, the reclamation of Caofeidian harbor area hinders the propagation of waves towards the shoals, and the wave heights are mainly distributed over the outer sea area. Compared with that before the project, the sediment concentration in the harbor area greatly decreases, and that in the outer sea area hardly changes.

After the 1-year implementation of the proposed scheme (Fig. 9), the erosion of the deep channel in front of Caofeidian is $0.15 \sim 0.48 \mathrm{~m}$ in depth, $0.09 \sim 0.27 \mathrm{~m}$ in depth in front of the west side, $0.00 \sim$ $0.20 \mathrm{~m}$ in depth in front of the east side, and $0.10 \sim 0.21 \mathrm{~m}$ in depth in the area $1.5 \sim 3.0 \mathrm{~km}$ away from Caofeidian island; the annual deposition of the channel of Laolonggou is $0.06 \sim 0.83 \mathrm{~m}$ in depth, and the back silting strength close to No. 3 harbor basin is larger. The annual back silting of No. 1 harbor basin is $0.35 \sim 1.31 \mathrm{~m}$ in depth, and its deposition point is mainly close to the backflow area near the mouth; that of No. 2 harbor basin is $0.02 \sim 0.99 \mathrm{~m}$ in depth, and deposition is larger near the mouth; that of No. 3 harbor basin is $0.03 \sim 0.64 \mathrm{~m}$ in depth, and the deposition point is close to the side of Laolonggou. It is predicted that deposition and erosion of the seabed in front of Caofeidian will reach the equilibrium (Lu et al, 2006) 2-3 years after the construction. The erosion in front of Caofeidian will be $0.3 \sim 1.1 \mathrm{~m}$ in depth, with the maximum about $2.1 \mathrm{~m}$. 
Sudden deposition of sediment caused by stormy waves In order to determine the sudden deposition of harbor basin and waterways induced by stormy waves, the strength of sudden deposition after the implementation of the proposed scheme is calculated by use of the co-action of waves (regular direction of SE with a deflection of 6 degrees) with the occurrence period of 10 years and spring and middle tides. The duration of waves is $48 \mathrm{~h}$. After the implementation of the scheme, wave heights are mainly distributed over the outer sea area, and during the middle tides the largest effective wave height is $3.8 \sim 4.1 \mathrm{~m}$. The sediment concentration at the west side of Caofeidian island is larger, up to 6.0 $\mathrm{kg} / \mathrm{m}^{3}$ (Fig. 10), and that in the harbor basin and Connecting River is small, about $0.5 \mathrm{~kg} / \mathrm{m}^{3}$.

After the implementation of the proposed scheme, under the action of waves with the occurrence period of 10 years, the deposition of No. 1 harbor basin is $0.01 \sim 0.21 \mathrm{~m}$ in depth, and its deposition point is mainly close to the mouth; that of No. 2 harbor basin is $0.00 \sim 0.20 \mathrm{~m}$ in depth, and it is larger near the mouth; that of No. 3 harbor basin is $0.00 \sim 0.07 \mathrm{~m}$ in depth, and the deposition point is in the sea area close to Laolonggou; the deposition in the channel of Laolonggou is large, up to $0.06 \sim 0.55 \mathrm{~m}$ in depth, and the strength of sudden deposition in the channel close to the mouth side is relatively large.

$\mathrm{Xu}$ et al completed physical model tests on mouth optimization of the proposed scheme for harbor basin No. 1 in March of 2007. The variation of the flow fields and the sediment deposition in the project area of harbor basin No. 1 were studied. On such a basis, the mouth layout of the harbor basin was optimized. The horizontal scale of the physical model $\lambda_{1}=720$, the vertical scale $\lambda_{\mathrm{h}}=120$, the variability is 6.0 , the wave height scale $\lambda_{\mathrm{H}}=100$, the wavelength scale $\lambda_{\mathrm{L}}=120$, the variability is 1.2 , and the model sand is employed by wood powder with the wet unit weight of $1.16 \mathrm{~g} / \mathrm{cm}^{3}$. Compared with the physical model test results, the velocities and flow regimes of harbor basin No. 1 and Connecting River are close, that is, at the mouth of harbor basin No. 1, water basically goes in during the flood tide period and out during the ebb tide period, and there occur large back flows. The physical model gives deposition situations of harbor basin under different shapes of breakwaters. The study shows that under the normal conditions, the annual mean deposition thickness at the mouth side of harbor basin No. 1 is $0.56 \sim 1.22 \mathrm{~m}$, which is close to to the value of $0.35 \sim 1.31 \mathrm{~m}$ calculated by mathematical model. Their distribution rules are agreeable, that is, the largest deposition area is close to the back flow area, and the more faraway from the mouth, the less the deposition.

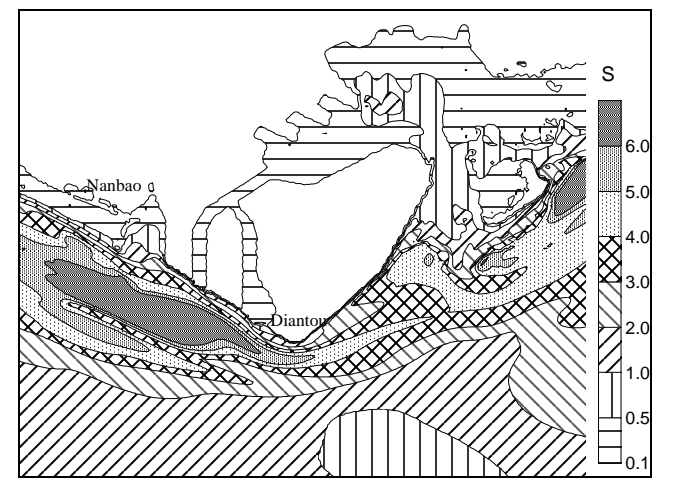

Figure 10. Suspended load concentration field after implementation of proposed scheme under action of SE waves with recurrence period of 10 years

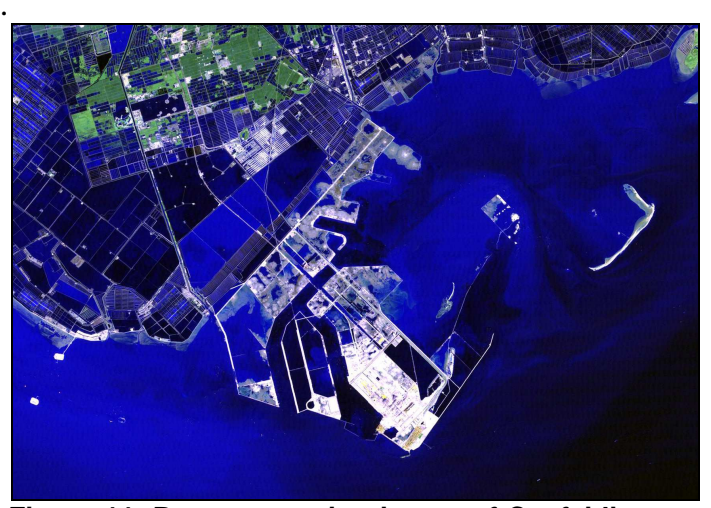

Figure 11. Remote sensing image of Caofeidian sea area in the end of 2008

\section{Stability of Deep Channel in Front of Caofeidian}

The stability of the deep channel in front of Caofeidian Island is one of the symbols for the stable shoals in Caofeidian sea area. The engineering practice shows that the reclamation area in Caofeidian offshore sea was about $30 \mathrm{~km}^{2}$ in the end of 2006 and was about $140 \mathrm{~km}^{2}$ (Fig. 11) in the end of 2008, and the deep channel in front of Caofeidian Island is the area for the main arrangement of deep-water berths. During 2004 2008, the sea area in front of Caofeidian Island has not changed of large deposition and erosion, and the depth contours in front of Caofeidian Island keep their original form (Fig. 12a). The seabed is basically in a state of deposition-erosion equilibrium with slight erosion, and the erosion range of the deep channel is about $0.5 \mathrm{~m}$ (Fig. 12b), indicating that the deep channel keeps its stability. Under the long-term oceanographic dynamic forces, the boundary and dynamic conditions for the deep channel are almost adaptive, and the seabed is basically in a state of stability. In recent years, the short sediment supply in Caofeidian sea area and the increase of headland effect aroused by 
the reclamation in front of Caofeidian Island result in an increase of hydrodynamic froces in local sea area in front of Caofeidian Island, and the deep chanel is in a state of slight erosion.

In 2006, the authors predicated the deposition and erosion variation after multi-step implementation of the proposed scheme: reclamation at Caofeidian embankment and excavation of harbor basin No. 1 and No. 2. The prediction indicates that the erosion in the deep channel in front of Caofeidian island would be $0.18 \sim 0.70 \mathrm{~m}$ during $2006 \sim 2008$ (Lu et al, 2006). The sea area within $1 \mathrm{~km}$ in length at both sides of Caofeidian island exhibits a slight deposition state owing to pile groups at the ore terminal. The erosion depth at $1 \mathrm{~km}$ away from the west side is $0.14 \sim 0.40 \mathrm{~m}$, and that $1 \mathrm{~km}$ away from the east side is $0.04 \sim 0.20 \mathrm{~m}$. It is close to the deposition-erosion variation (Fig. 12b) aroused by projects in 2008. It should be noted that a sand dredging pit at the site about $1.3 \mathrm{~km}$ away the east coastal side is beyond the range a mathematical model could predict.

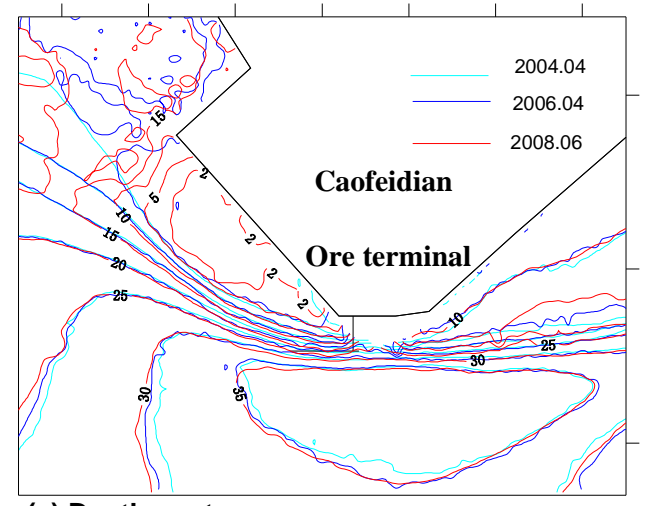

(a) Depth contours

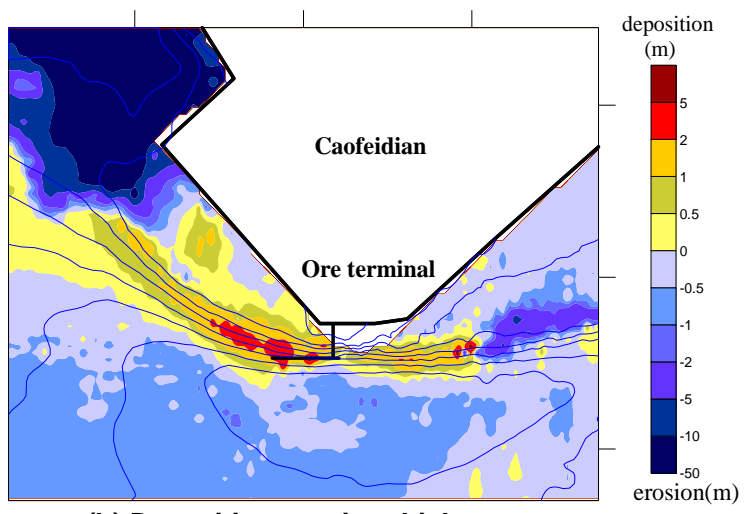

(b) Deposition-erosion thickness

igure 12. Distribution of depth contours and deposition-erosion depth of deep channel in front of Caofeidian during 2004 2008

\section{CONCLUSIONS AND SUGGESTIONS}

The offshore sand barrier-lagoon oceanographic system of Caofeidian sea area is formed by old Luanhe River delta under the co-action of waves and tidal currents after the diversion of Luanhe River. The tidal currents are the main dynamic forces for the formation and maintenance of water depth of deep channel of the modern tidal inlet. The development of the deep channel of the tidal inlet in front of Caofeidian has certain geological structural basis: the headland topography induced by sandy islands is the boundary condition for the deep channel, and the consequent increase of local tidal currents is the dynamic condition for the deep channel. Due to the restraint action of the narrow entrance of the Laolonggou tidal inlet, the induced increase of flow velocity is the main dynamic force for the maintenance of water depth of the deep channel. The oceanographic topography in Caofeidian sea area has a long time for development. The offshore sand barriers such as Caofeidian and Dongkengtuo have thick foundations and become stable sandy islands. Furthermore, there is a small deposition rate in the deep channel of the tidal inlet. Therefore the shoals will be basically stable for long time. Simultaneously, owing to insufficient coastwise sediment supply, the outer edges of Caofeidian and Dongkengtuo will exhibit slight erosion in future. With the development of Caofeidian sea area, various human activities will have increasing effect on its dynamic conditions and topographical evolvement. They have reached the magnitude of influences by natural factors. At some certain coastal area, the human activities have become the dominating factor for the evolution tendency of deposition and erosion of shoals and channels.

Estimation of effects of the implementation of the proposed scheme shows that the flow velocity slightly increases in front of Caofeidian foreland, and decreases in the habor basin and channels. Since the mean water depth above the shoals is less than $1 \mathrm{~m}$, the tidal prism decreases silightly after the reclamation. Thus, the developments of the harbor area have little effect on the hydrodynamic environment. Compared with that before the project, the suspended sediment concentration in the harbor area significantly decreases, and that in the outer sea area has little change. After the implementation of the proposed scheme, the deep channel in front of Caofeidian foreland is in a state of erosion, and the harbor basin and channels exhibit a state of deposition. It is predicted that erosion and deposition of the seabed in front of Caofeidian foreland will reach the equilibrium $2 \sim 3$ years after the construction. The engineering practice shows that during $2004 \sim 2008$, the sea area in front of 
Caofeidian Island generally did not change in terms of erosion and deposition, and the depth contours in front of Caofeidian Island will keep their original form. The seabed is basically in a state of erosiondeposition equilibrium with slight deposition, and the deep channel is stable. The stability of the deep channel in front of Caofeidian foreland indicates that the layout scheme of "island in the front and land at the back" as well as an excavated harbor basin consists of various tidal inlets is rational.

With regard to the development and exploitation of Caofeidian sea area, the short-term and longterm influences of sediment supply should be fully and comprehensively considered not only from the positive aspect (e. g., decrease of back deposition in harbor and channels) but also from possible negative aspect, and feasible and effective policies and measures should also be proposed. In addition, During construction the hydrological, sediment and topographical monitored during the construction period should be strengthened so as to find and solve problems in time..

\section{ACKNOWLEDGEMENT}

This research was supported by the National Natural Science Foundation of China (Grant No.50879047 and No.50779037). The authors would like to thank Prof. Xu Xiao, Prof. Zhang Jinshan, Prof. Pan Junning, Prof. Wang Hongchuan, Senior Engineer She Xiaojian, Engineer Zhang Weisheng and graduate student Li Shouqian for their participation, and Prof. Liu Jiaju and Prof. Huang Jianwei for their assistance.

\section{REFERENCES}

JI Rongyao. 2008. Morphodynamic processes and engineering reaction of tidal channels-taking Caofeidian nearshore area in Bohai bay for example. Report of Nanjing Hydraulic Research Institute. (in Chinese)

Liang Yingchen. 2008. My work participatived about demonstration of construction of Caofeidian harbor. Zongheng (Journal of the Two Conferences--Speical issue of Caofeidian, Tangshan), 29-33. (in Chinese)

Lu Yongjun, ZuoLiqin, Shao Xuejun et al. 2005. A 2D mathematical model for sediment transport by waves and tidal currents. China Ocean Engineering, 19(4): 571-586

Lu Yongjun, Xu Xiao., Zuo Liqin, et al. 2006. Mathematical model of waves, tidal currents and sediment for Caofeidian harbor area of Tangshan Port and researches on stability of shoals and channels. Report of Nanjing Hydraulic Research Institute. (in Chinese)

Lu Yongjun, Ji Rongyao, Zuo Liqin, et al. 2007. Study on Hydrodynamic and sedimentation problems in development of harbors located at bay-type tidal inlet. Journal of Chinese Hydraulic Engineering, 38(12): 1426-1436. (in Chinese)

Lu Yongjun, Zuo Liqin, Ji Rongyao, et al. 2007. Effect of development of Caofeidian harbor area in Bohai Bay on hydrodynamic sediment environment. Advances in Water Science, 18(6): 793-800. (in Chinese)

Lu Yongjun, Zuo Liqin, Ji Rongyao et al. 2008. Effect of Development of Caofeidian Harbor Area in Bohai Bay on Hydrodynamic Sediment Environment. China Ocean Engineering, 22(1): 97-112

Lu Yongjun, Ji Rongyao, Zuo Liqin. 2009. Morphodynamic responses to the deep water harbor development in the Caofeidian sea area, China's Bohai Bay, Coastal Engineering, 56(8): 831-843

Qiu Dahong. 2008. Ideas about development of Caofeidian sea area. Zongheng (Journal of the Two Conferences-Speical issue of Caofeidian, Tangshan), 74-75. (in Chinese)

Su Jilan, 2005. Hydrology in the China Sea. Beijing, Ocean Press. (in Chinese)

Wang Ying, Wang Yaping, Zou Xinqing. 1997. Investigation on coastal dynamic geomorphology in Caofeidian harbor area of Jingtang Port. Report of Nanjing University. (in Chinese)

Wang Ying, Zou Xinqing, Wang Yaping. 2006. Study on coastal dynamic geomorphology for development of Caofeidian harbor area of Tangshan Port. Report of Nanjing University. (in Chinese)

$\mathrm{Xu}$ Xiao, 1997. Analysis of sediment motion and trend of deposition and erosion in Caofeidian harbor area of Jingtang Port. Report of Nanjing Hydraulic Research Institute. (in Chinese)

Xu X., She X. J. 2007. Study on sediment motion and flow field of excavated harbor basin and channels with different breakwaters in the Caofeidian sea area by use of physical model. Report of Nanjing Hydraulic Research Institute. (in Chinese)

$\mathrm{Xu}$ Xiao. 2008. Study on physical model of flow field and researches on stability of shoals and channels in Caofeidian sea area. Zongheng (Journal of the Two Conferences--Speical issue of Caofeidian, Tangshan), 3436. (in Chinese)

Yang Hua. 2006. Analysis of change of deposition and erosion for Caofeidian Ore Terminal. Report of Tianjin Research Institute for Water Transport Engineering. (in Chinese)

Zhang Minghui and Sun Lu. 2006. Study on construction conditions and schemes of Caofeidian harbor area of Tangshan Port. Report of Traffic Planning Research Institute. (in Chinese) 